\title{
How Can Humanities Interventions Promote Progress in the Environmental Sciences?
}

\author{
Sally L. Kitch \\ School of Social Transformation, Arizona State University, Tempe, AZ 86287-6403, USA; skitch@asu.edu
}

Received: 30 August 2017; Accepted: 6 October 2017; Published: 16 October 2017

\begin{abstract}
Environmental humanists make compelling arguments about the importance of the environmental humanities (EH) for discovering new ways to conceptualize and address the urgent challenges of the environmental crisis now confronting the planet. Many environmental scientists in a variety of fields are also committed to incorporating socio-cultural analyses in their work. Despite such intentions and rhetoric, however, and some humanists' eagerness to incorporate science into their own work, "radical interdisciplinarity [across the humanities and sciences] is ... rare ... and does not have the impact one would hope for" (Holm et al. 2013, p. 32). This article discusses reasons for the gap between transdisciplinary intentions and the work being done in the environmental sciences. The article also describes a project designed to address that gap. Entitled "From Innovation to Progress: Addressing Hazards of the Sustainability Sciences", the project encourages humanities interventions in problem definition, before any solution or action is chosen. Progress offers strategies for promoting expanded stakeholder engagement, enhancing understanding of power struggles and inequities that underlie problems and over-determine solutions, and designing multiple future scenarios based on alternative values, cultural practices and beliefs, and perspectives on power distribution and entitlement.
\end{abstract}

Keywords: environmental science; humanities; progress; innovation; stakeholders; scenarios; communication; problem identification; solution proposal; values; epistemology; language; power relationships; social justice; knowledge communities; transdisciplinary

\section{Introduction: The Aspirational Impact of Environmental Humanities on Scientific Environmental Research}

"If wishes were horses, then I'd have a ranch," croons singer Lucinda Williams. By that logic, if scholars' many wishes and good intentions were actual research strategies and methodologies, then "radical interdisciplinarity" across the sciences and humanities would now be uniting scholars in saving the planet. Alas, however. a gap still exists between declarations of the need and desire for such radical interdisciplinarity (or transdisciplinarity) and the reality,. As Holm et al. have observed, radical interdisciplinarity "is ... rare ... and does not have the impact one would hope for" (Holm et al. 2013, p. 32). ${ }^{1}$

The news is not altogether bleak, as there are some recent signs of progress toward the goal of radical interdisciplinarity. For example, a recent issue of the climate science journal, Global and Planetary Change (September 2017) features fully peer-reviewed articles by humanities scholars, including

1 Although Holm et al. do not employ the term "transdisciplinarity", I take their phrase "radical interdisciplinarity" to connote exactly that. What those writers and others appear to envision entails going beyond multidisciplinarity and interdisciplinarity to develop "new insights, knowledge and decision-making" across disciplinary lines (Brown et al. 2010, p. 302). Or as I have described it elsewhere, transdisciplinarity entails integrative and reciprocal knowledge exchanges across disciplinary boundaries. That is, knowledge exchanges actually alter the contributing disciplines, as in the blending represented by biochemistry. See (Kitch 2007, pp. 126-30). 
"Climate Change Studies and the Human Sciences", by Poul Holm and Verena Winiwarter. It also appears that both humanists and scientists now broadly accept the concept of the Anthropocene, despite the term's limitations and controversial status in some quarters. Brondizio et al.'s survey of the Web of Science Data Base reveals that the term appeared from 2000 to 2015 in both earth and environmental sciences articles (64 percent) and in the humanities and social sciences (24 percent). (Beyond that data base, more evidence of the term's acceptance in environmental humanities [EH] publications would likely surface.) Considering even that limited sample, the authors see the potential for "the Anthropocene concept ... to bring together contributions from multiple knowledge branches, and also from wider stakeholder communities, around the complexities of global change and sustainability." At the same time, however, the authors note that differences in the term's interpretation highlight "disciplinary limitations, epistemological tensions, language gaps, and political narratives", which are "likely to perpetuate fragmented research agendas and to reinforce disciplinary boundaries and stereotypes" (Brondizio et al. 2016, pp. 320, 322). Thus, two steps forward, one step back.

Perhaps more promising, it appears that at least some scientists have entered the realm of the humanities by "offering exhilarating histories of the earth, long-term evolutionary sagas, and narratives of humans as a species" (Griffiths 2007). Others have accepted humanists' accounts of global inequalities and historical disparities, as well as social and cultural differences in values and perspectives, as underlying causes as well as consequences of global environmental change (GEC). Such scientists understand that the Anthropocene is not a consequence of universal human activity around the world "but [is] rather the result of a particular history of global economic and political arrangements." They also recognize that those "arrangements" continue to "operate and shape regions and populations, as well as "national structural adjustment policies, and to promote resource extraction, with disastrous consequences" (Brondizio et al. 2016, p. 322).

Most promising, there is evidence that many environmental scientists WANT to interact with environmental humanists and social scientists (ESSH). The director of Arizona State University's Global Institute for Sustainability (GIOS), Gary Dirks, who is also a chemist and an expert on energy transition, is among them: "The problems of sustainability are not, in the first instance, scientific or technological problems," he says. "Rather, they are human problems." The journal Science has even declared that environmental "'research dominated by the natural sciences [should] transition toward research involving the full range of science and humanities'" (Castree et al. 2014, p. 764). A recent survey of scientists interested and experienced in research at the human-environment interface has also "identified many advantages and rewards of interdisciplinary research, including the creation of more-relevant knowledge" (Roy et al. 2013, p. 745). Similarly, a group of engineers, after lamenting the fragmentation of sustainability research - "with a range of academic disciplines and professional organizations pursuing similar goals, but without much formal coordination"-note that integrating "environmental, economic, and social aspects" of sustainability, via new educational and organizational structures, could improve prospects for needed interdisciplinary integration" (Little et al. 2016, p. 6830). In the field of ecosystem-service valuation, which measures the value of nature in monetary terms, environmental scientists are "calling for a deeper understanding of how less tangible, nonmaterial values shape management and stakeholder decisions", a need that reflects $\mathrm{EH}$ priorities and arguments (Van Riper et al. 2017, p. 233). Some environmental social scientists are also questioning their own "reductionist approaches to science, communication and decision-making", by calling for diversity in project teams (including both researcher identities and disciplines) and for embracing ambiguity, using examples from the arts and humanities (Fleming and Howden 2016, p. 1271).

Despite such encouraging rhetoric and intentions, however, as well as praise for and acceptance of EH perspectives, wishes have not yet produced a ranch where the practice of environmental sciences 
and the insights, recommendations, and analyses of ESSH are perfectly integrated. ${ }^{2}$ Evidence suggests that the disconnect between the environmental sciences and EH persists despite environmental humanists' valiant efforts. Indeed, they have offered compelling arguments for years that demonstrate how real cooperation across disciplines could improve the quality of environmental science research, including by better articulating research questions that take full advantage of multiple viewpoints. Sverker Sörlin, for example, argues pointedly for reconfiguring the concept of environmental expertise to include the humanities and social sciences. He claims that such a change is necessary in order to counter the tendency of scientific research to reduce causes, impacts, and remedies to things that can be counted. Such reductive methods imply that numbers are more neutral and authentic than words, when understanding language and beliefs is actually the crux of the matter. "Science's hegemony as the basis of expertise is part of the problem," writes Sörlin. In particular, science cannot contribute to the political realm in which GEC must be tackled. "Humanities' focus on ethics, value formation, concepts, ideas, and decision-making, based on reservoirs of historical and cultural knowledge, [is what's] necessary for taking on the enormity of future global change. The reasons for the problems are religious, ideological, and habitual, yet scientific descriptions of the state of the world usually omit people, citizens, and societies" (Sörlin 2013, p. 22). Poul Holm et al. further note that the humanities embrace uncertainty and contingency, which are key aspects of GEC. Because the sciences eschew uncertainty and contingency, new approaches and radically new alignments of disciplines are required to remedy the inequities of "where we meet" as disciplines right now, so we can address those elements of GEC (Holm et al. 2013, p. 31).

Holm and other humanists also argue that EH "enframing" of environments and the way human value systems, practices, imaginations, and identities have shaped them would also improve environmental scientific practice. For openers, the scientific dualism nature-culture needs reframing, possibly as Donna Haraway's "naturecultures." Such change would generate new understanding of the ways in which nature is continuously being reshaped by human arrangements and networks (Holm et al. 2013, p. 31).

At the same time, environmental humanists point to parameters and habits of scientific research methodologies and field identification as formidable barriers to radical interdisciplinarity. For example, Noel Castree et al. argue that environmental scientists have typically "analyzed people and the biophysical world using similar concepts and protocols, with the goal of helping people reduce or cope with the disruption of Earth systems." That approach not only over-generalizes the human role in GEC, but it also risks perpetuating "complicity with existing social systems." That is, "by refusing to explore the full range of values, means and ends that might guide human responses to GEC, researchers may implicitly endorse the societal status quo by neglecting to question it fundamentally." That approach also helps to conceal the ways in which science and technology "internalize and reproduce certain values without seeming to." In addition, according to Castree et al., environmental scientists seem to imagine a single "preferred future awaiting 'objective' analysis if only we had more data or better models", whereas EH perspectives favor a "diversity of 'values-means-ends' packages" (Castree et al. 2014, pp. 764-66).

Brondizio et al. identify the "human dimensions of GEC" as a problematic concept, despite its prominence in the environmental sciences. The authors argue that the phrase may drive researchers to

2 Although it is beyond the scope of this paper to define them, the insights of ESSH include the definitions of various sub-fields, including environmental studies (Soulé and Press 1998), ecological humanities (Merchant 1980; Eckersley 1998; Griffiths 2007), and ethnoecology—especially the study of indigenous ecological knowledge based on empirical observation and embedded in a system of ethics (Rose and Robin 2004). Larger ESSH insights include recognition that "the unit of survival" is not the individual or species but rather the relationship between organisms and their environments. ESSH insights also include: the need to embrace uncertainty in the environmental sciences; the importance of situated rather than universal knowledge; the replacement of prediction with probabilities; the merging of ecology, history, place and people in "three-dimensional analysis"; the importance of historicizing and "narrativizing" ecological problems; and the need to dismantle the nature/culture divide through an understanding that both are historical, interdependent, and evolutionary (Rose and Robin 2004; Griffiths 2007). 
see humans as a unitary, undifferentiated, global culprit in environmental degradation. Humanists, on the other hand, typically stress historical, cultural, political, and economic differences among humans, within and across regions, that are crucial to a full understanding of the Anthropocene. Thus, humanities interpretations are more differentiated and historically, politically, and culturally situated than scientific ones (Brondizio et al. 2016, p. 319). Together with social scientists (but with different methodologies), humanists also study intangible values and other perceptions and internal processes within the individual: "value orientations, beliefs, attitudes, emotions ... identity, perceptions, and attitudes", some of which change over time and some of which are fixed (Van Riper et al. 2017). Moreover, along with the arts, the humanities help to "disabuse humanity of its naïve, often vainglorious commitments: to remind us of the limits of our ambitions, even of our ambitions for sustainability. [They return] us to our vulnerabilities [and help] to cure us of complacent over-abstraction" (Stables 2013, p. 184).

Methodological differences also distinguish the EH from the SSH and shape scholarly perspectives on humans' role in causing and addressing the crises of the Anthropocene. For example, social scientists tend to regard human behavior as a priori and to measure intangible and invisible motivations and beliefs on the basis of subjects' reports, actions, and choices. Humanists, on the other hand, tend to regard beliefs and motivations as a priori to actions and behavior, though not transparently so. That relationship is inevitably complex and subject to influences, variations, and interpretations. Andrew Stables argues that such a difference in perspectives on "the human" may affect definitions of concepts such as sustainability: which comes first, sustainability as a "regulative ideal" (per Kant) that shapes both attitudes and actions? Or do sustainable actions both prefigure and reflect reliably sustainable attitudes and beliefs about the environment (Stables 2013, p. 180)? The answer may determine a researcher's agenda.

As important as they are, these methodological and conceptual differences among the humanities, sciences, and social sciences may actually be trivial compared with the institutional barriers, communication difficulties, disciplinary habits, and rankings of disciplines in the academic hierarchy. In their 2013 Bioscience study, Roy et al. report that 61 percent of environmental scientist respondents named institutional barriers, including tensions within departments and lack of credit for interdisciplinary work in promotion and tenure decisions, as the real obstacles facing radical interdisciplinarity in environmental research (Roy et al. 2013, p. 745). But even those concerns may be only the symptoms of structural obstacles to the radical interdisciplinarity necessary to transform GEC research (Benneworth et al. 2016). Beneath issues of credit and tenure lies the increased pressure on universities in the U.S. and Europe to justify their existence or funding through measurable evidence of innovation.

The emphasis on innovation in today's universities has had multiple and cascading effects on the nature of scientific work and on perceptions of the value of humanities research. For example, public and private funding may depend on an institution's "capacity to stimulate innovation", especially with regard to grand challenges that many funders and politicians believe can only be addressed by so-called "useful" disciplines. In this research climate, ivory tower scientists have taken a back seat to entrepreneurial scientists, who seek successful application of their work beyond the academy. The model of that kind of scientific work is the pharmaceutical spin-off company. Thus, even if researchers and policy makers recognize the value of humanities research, they may cling to simplistic models of the relationship between research and social benefits. They may also imagine that the public demanding quick research results—typically actions—are "miserly taxpayers." Those grumpy taxpayers presumably regard social and cultural impacts as less valuable than economic impacts, despite evidence from surveys like the REF Impact Pilot in the UK that indicate public acceptance of arts and humanities research as just as "impactful" as research in STEM disciplines. Nevertheless, funders and "policy-makers often take as common sense" that returns on investment in the arts and humanities are "second best to those disciplines." There may also be a sense that the "problem-owners" of humanities research are other humanities scholars, rather than the users of the 
research, as with entrepreneurial science. Humanists may contribute to that perception, according to Michael Berubé, when they refuse to justify or even discuss "'their disciplines in terms of social utility'" (Benneworth et al. 2016, pp. 42, 45, 17). ${ }^{3}$

All of these factors can add up to a somewhat negative or wary view of the humanities by scientists, especially those who have been winners in the academic quest to produce well-funded use-value research. Even environmental scientists who recognize the value of humanities research, therefore, might be reluctant or unsure about how to partner with colleagues who are less successful in the competitive funding marketplace. Entrepreneurial funding models do not easily accommodate the radical interdisciplinarity that might actually alter environmental scientific methods and research questions.

\section{All That Glitters Is Not Bold: A Humanities Intervention in Environmental Scientific Research}

The obstacles discussed above seem to make the prospects of wide-scale, meaningful radical interdisciplinarity across the humanities and sciences rather dim. Certainly, humanists alone cannot overcome the institutional barriers and social and political climate for higher education merely with their compelling arguments pressing the need for transdisciplinarity. Perhaps the limits of that approach are analogous to the failure of science alone to persuade reluctant publics, industrialists, and politicians about the urgency of today's environmental crisis with increased data and logical argument. Facts by themselves do not seem to win heavily weighted political contests these days. Wisely, many environmental humanists have chosen instead to generate radical interdisciplinarity on their own by immersing themselves in the topics that environmental scientists care about-from ocean acidification, to GMOs, to wildlands restoration, to energy transition. This volume of Humanities demonstrates the results of that engagement, many of which demonstrate impressive impact.

The humanities-centric project described below takes a different tack by defining a direct intervention in the practices of environmental science. ${ }^{4}$ Entitled "From Innovation to Progress: Addressing Hazards of the Sustainability Sciences" (nicknamed Progress) the project seeks to engage with the processes of constructing scientific research initiatives and of proposing solutions to environmental concerns, regardless of the subject matter of those initiatives. Progress is the creation of a group of humanists, social scientists, and scientists at Arizona State University-including Gary Dirks, Cynthia Selin, and myself, among others. ${ }^{5}$

The project's title reflects our group's insight into one of the drawbacks of innovation as a guiding principle, both in general and in environmental research in particular. That is, the pursuit of innovation can be a diversion from achieving actual progress in diminishing environmental degradation, mitigating environmental hazards, or increasing the chances of long-term human survival. Although the term innovation is often presumed to encompass the concept of progress, our project counters that presumption by raising the standards for claiming the much rarer outcome of actual improvement in the conditions of the planet or mitigation of environmental catastrophe-i.e., making progress.

A key drawback to pressing for innovation is the tendency to associate it with technological or material advances that may serve the interests of and relationships among researchers and

3 For further discussion of the REF Impact Pilot, see (Benneworth et al. 2016, pp. 36-38).

4 I say "humanities-centric" because Progress partners also include social scientists, artists, and engineers who see themselves as humanists pursuing EH methods and goals.

5 Gary Dirks is Director of the Julie Ann Wrigley Global Institute of Sustainability. Cynthia Selin is Associate Professor, School for the Future of Innovation in Society and Founder of the Center for the Study of the Future. Sally Kitch is University and Regents' Professor, School of Social Transformation; founding director of the Institute for Humanities Research and Humanities Lab. Other contributors to the project include Joan McGregor, Professor of Philosophy, School of Historical, Philosophical, and Religious Studies, and Sha Xin Wei, Director of Arts, Media, and Engineering, Herberger Institute of Design and the Arts. All team members work at Arizona State University, which is the headquarters of the North American Observatory of the Humanities for the Environment international project. 
manufacturers better than they address the deeper problems, causes, and questions underlying the symptoms of GEC. Indeed, the quest for innovation may actually drive researchers to define problems in ways that promote technological or other material solutions. Thus, promoting innovative solutions might result in shrinking problems to a size that technologies favored by interested parties can resolve ahead of or instead of probing the deep nature of the problem. Indeed, Maren Mahoney, Strategic Initiatives Coordinator of ASU's Energy Policy Innovation Council, commented to our team that "the specific power dynamic of" researchers' interactions often "ends up determining which solution(s) is chosen rather than the merits of the case."

This "tail wagging the dog" approach might be fine if it produced what we define as progress on climate change, biodiversity loss, and warming, polluted, and acidifying oceans. However, new technologies and enterprises based on scientific and engineering research have by themselves achieved only limited success in advancing such progress, in large part because attaining political or public consensus on the need for and costs, consequences, or value of those technologies and enterprises has been difficult, to say the least. In addition, solutions that shortchange deep problem analysis may be partial or even counterproductive, especially as they collide with or undermine other solutions or create new problems.

Such has been the case with the production of biofuels as a solution to U.S. dependency on fossil fuels. Those who advanced that technology vastly underestimated the effects on the environment and food supply of the massive land use changes required by large scale biofuel production. Between 2006 and 2011, for example, U.S. farmers converted more than 1.3 million acres of grassland into corn and soy bean fields, in large part to grow biofuel crops that the government subsidized. However, the loss of grasslands reduces the soil's carbon sequestration capability so much that "fuels like corn ethanol and soy biodiesel lose a portion of their carbon advantage over gasoline if farmers are simply digging up virgin grassland to grow the crops" (Plumer 2013).

Without understanding human motivations and values, not to mention possible environmental impacts, such unintended consequences are too easily aggravated by technological solutions developed in isolation. That is why Progress collaborators, including scientists, agree with most environmental humanists that achieving genuine progress on complex, wicked environmental problems depends upon understanding and addressing those problems as a human challenge, which entails vexed relationships between natural and human systems, including power hierarchies, systems of thought, and patterns of belief, denial, and resistance, as well as behavior and practices.

Thus, Progress begins where we think the human challenge begins: with the processes of framing and defining problems and identifying solutions. In addition, Progress tackles the disciplinary hierarchy that has been such an obstacle to the radical interdisciplinarity GEC requires. The project offers to enhance the effectiveness of environmental science research in ways scientists have been asking for-by providing what is missing in scientific approaches to environmental challenges.

Progress also offers a benefit for the humanities by helping to demonstrate that $\mathrm{EH}$ can be generative and socially impactful, not only by producing theories, ideas, conferences, books, and articles but also by inspiring and shaping science itself. A project's outcomes might involve technology, but they must also be based on understanding the ways in which conflicting and varied human ideas, assumptions, habits, values, and behavior create, enhance, and impede natural systems. Humanities-inspired actions can also offer new parameters for measuring and addressing the fraught relationship between natural and human systems by promoting changes in policies, communication structures, and power relationships. Through this approach, Progress demonstrates that humanities-centric research can have users and problem owners beyond humanists.

In addition, the design of the Progress project addresses the relationship between global environmental issues and local problems. That is, while human-induced environmental challenges interconnect across states and cultures, they also vary by the particularities of location and stakeholders, as well as by communities' histories, values, and networks of relationships beyond their boundaries. Progress focuses on the local or regional because that is often where interventions can have the most 
impact. At the same time, the project brings local stakeholders' attention to interconnected challenges across cities, states, and nations.

Taking both interconnection and specificity into account, the Progress Method utilizes a portable strategy that can be adapted for specific situations and issues, from rising sea levels in coastal cities, to desertification, to insecticide or fertilizer run-off in freshwater streams, to polluted urban water supplies. The Progress Method can also be adapted for partnership with a wide variety of environmental science research projects that would typically advance new technologies for everything from wide-scale carbon-capture to water purification projects in small villages in Africa. What makes the method adaptable and portable is its universe of common but not fixed factors that are likely to intertwine with environmental problems around the globe. Those factors include the historical, epistemological, cultural, and political contexts and struggles over power and equity that are implicated in many environmental challenges. In various situations interrogating those factors can reveal conflicting cultural, aesthetic, or moral values, comforting or self-aggrandizing stories people tell about themselves and their communities, evidence of denial and hidden assumptions, communication problems, and/or social inequities. In addition, the Progress Method recognizes that a common root of many environmental challenges is hubris about humans' right—even mandate- to master Nature.

The Progress Method is designed to make visible the assumptions, beliefs, values, and power relationships that are typically suppressed in problem identification and solution proposal processes but often drive those processes nonetheless. The method relies on three strategies or tool kits that can (and must) be adapted to particular situations. These strategies have evolved not only from the perspectives of humanists deeply involved in EH but also through a year of discussions with environmental scientists and social scientists, some of whose responses to our initial survey are included in the tool kit descriptions below ${ }^{6}$ :

- The Stakeholders Toolkit expands engagement frameworks and strategies by first expanding the group of stakeholders and interested parties involved in or affected by the environmental concerns being addressed. This is a key component for reducing the possibility of problem oversimplification. "Multiplicity and diversity [that] can help make complexity visible" offer the best antidote for that possibility, according to Clark Miller of ASU's GIOS and School for the Future of Innovation in Society.

Multiplicity and diversity are the goals of the Progress stakeholder strategy, as it first tackles the habits of exclusion and discrimination-including racial and gender discrimination-that impede the identification of relevant stakeholders. Diversifying and expanding participating stakeholders serves dual purposes. The first is advancing social and environmental justice. The second is expanding the knowledge base on which the deepest aspects of environmental problems are defined and appropriate solutions are selected.

The Stakeholder Toolkit connects those two purposes by working with principals to make the pool of stakeholders more representative of groups often overlooked in community decision making and by demonstrating that empowering a more diverse pool improves the generation of knowledge leading to problem identification and solution selection. Making stakeholder groups more diverse also brings needed attention to conflicts among community members' priorities, politics, assumptions, and interpretations of facts, as it also expands the academic and social knowledge communities, especially minority and indigenous communities, that will synthesize data and analyze the relationship between diverse human cultures and their environments. Toolkit exercises help to tie the social dimensions of knowledge generation-which often reflect

6 Progress has competed in a process at ASU known as "Decisive." That competition involved presentations to university administrators and faculty from multiple disciplines, including many in the natural sciences. The Decisive process is on-going but could result in seed funding for Progress as one of a handful of projects the university deems central to its transdisciplinary research mission. 
individuals' and groups' social status and location-to the assumptions and truisms stakeholders might bring to deliberations. Discussions reflect on the contribution of such differences and hierarchies based on race, gender, and economic status to the environmental problems the group is addressing.

Toolkit exercises further help all participants recognize how they have been trained or raised to understand reality and to address problems, as well as the possible limits of that training for understanding the ever unfolding, heterogeneous, and dynamic complexity of the world in general and of the particular problems the group faces. Exercises also demonstrate the provisionality and plurality of all ways of knowing, making "knowledge about how the world is and will be in the future ... far from certain" (Russell 2010, p. 37), even as some people-especially conventional experts-might mistake their own perspectives for certainty (Grootjans 2010, pp. 230-32).

In addition, the Stakeholder Toolkit reminds decision-makers that the people addressing and seeking to solve the wicked problems of environmental sustainability may be trapped in the same assumptions, rationalizations, power relationships and epistemological habits as those who have caused the problems in the first place. Indeed, in some cases, they may be the same people. Thus, the Stakeholder Toolkit seeks to expose and transform those habits. One strategy for doing so is what aboriginal scholar Kerry Arabena calls "practicing indigenous knowledge" in order to nudge stakeholders into alternative ways of knowing by first exploring their existing epistemologies. Arabena suggests asking participants to consider questions such as: "When do I listen? What are my ceremonies? ... What is sacred? ... What am I prepared to die for? What would make we want to live? ... What am I held by? What is the largest construct that holds me?" While deliberations about environmental issues often begin as confrontations between adversarial perspectives, Arabena explains that indigenous knowledges emphasize interconnection. Embracing that value, the Stakeholder Toolkit asks participants to contemplate how they and their interests are interconnected with everyone else's (Arabena 2010, pp. 264-65).

To that end, the toolkit also encourages multiple framings of the environmental problem(s) the community or region faces. Those framings further help to define points of conflict, power dynamics, and varied cultural values, epistemologies, and perspectives that have contributed to the problem or might impede its solution. In addition, the toolkit encourages what Jacqueline Russell calls "a social process of critical deliberation" that requires participants to justify their interpretations of facts, processes of reasoning, and perspectives on the possible consequences of any decision. That process further requires participants to reveal and discuss underlying values, assumptions, and interests (Russell 2010, p. 56).

The Stakeholder Toolkit's strategies for identifying conflicts and possible points of convergence in historical and contemporary power relationships, varied ethical systems, versions of the facts, and assumptions, as well as multiple problem framings, is designed to produce a broader and deeper understanding of the environmental/social/cultural challenges facing decision-makers. Pre- and post-exercise assessment of those aspects of problem identification includes composing various types of narratives about the human roots of the environmental challenges facing the community. Participants are first asked to compose individual accounts of those roots in their local situation. As the exercises unfold, they then revise those accounts through small group and larger group collaborations on definitions of the deepest understanding of the problem(s) at hand. From there, participants move on to the strategies of the Futures Toolkit, which builds upon that expanded understanding to the consideration of the remedies or actions most appropriate to the presenting problem(s).

- The Futures Toolkit facilitates the process of negotiation, reconciliation, and synthesis by promoting futures thinking that is historically and culturally grounded but also boldly imaginative. Rather than prescribing a single future, the Futures Toolkit invites the production of multiple future scenarios that reflect the various framings of the community's environmental challenges, 
already identified, as well as the varied knowledge communities, values, and cultural perspectives assembled around the table.

The Futures Toolkit proposes that alternative visions might be equally desirable. At the same time, the process helps to identify possible intersections among preferred scenarios, even when assumptions and basic premises differ. Myths may play a role in making such links among alternative future visions, because myths "enable us to tackle problems collectively with complete strangers", even as they can "stand in the way of progress", according to Bill Brandt, Director of Strategic Integration, ASU Lightworks. Recognizing both aspects of myths can advance Futures work.

As Cynthia Selin et al. explain, scenario building exercises help users to rehearse alternative futures through co-inquiry, including "multiple phases of research, peer-review, and reflection." Ideas are developed and refined through collaborative testing. Some ideas may be disposed of and then resurrected. The process improves the clarity and intelligibility of surviving ideas. Scenario building is also designed to help participants experience rather than just contemplate alternative futures, as well as to examine the present from a distant perspective. Scenarios are "structured imaginations" communicated through stories, pictures, films, props, performances, or shared artifacts from the future, such as street signs, magazine cover designs, maps, or product packaging. The point is to provide an opportunity for participants to experience and try on unfamiliar perspectives on the present and future and possibly to create new mental models (Selin et al. 2015, pp. 10-15). Scenario building exercises are therefore meant to cause enough discomfort to be of cognitive help in the process of reframing problems and solutions. Instead of rushing to consensus, scenario builders can often benefit from pausing, "staying with ambiguity and delving into ignorance" as they make decisions (Ramírez and Selin 2014, p. 68).

The Futures Toolkit is designed to move stakeholders to the point of action(s) to address the environmental challenge(s) before them. Technological innovation may be part of the solution chosen, but addressing the deeper cultural and political factors implicated in both the causes of and solutions to the challenge(s) is of equal or greater importance than such innovation. Stakeholders may recognize several courses of action and try to synthesize or bundle them in going forward. In many cases, solutions will be incremental rather than sweeping, with mechanisms for evaluation built in so that the solution course can be revised or altered to accommodate changing circumstances or setbacks.

- The Collaboration Toolkit intersects the Stakeholder and Futures toolkits. It includes techniques for structuring productive but difficult conversations through meaningful dialogue, reflection, the mindful suspension of judgment, and creating new narratives and broader paradigms for approaching sustainability problems. Strategies crucial to achieving that outcome include developing empathy and trust through storytelling, the collective composition of scenarios and problem and solution narratives, and exploring possible convergences among diverse groups' hopes and concerns. This core intervention counters the tendency of people "to talk past each other", as Maren Mahoney observes.

The Collaboration Toolkit offers a suite of deliberative engagement protocols that enable group learning and decision-making. Among them are various game techniques and material deliberations that allow safe risk taking. Games designed to promote epistemological and social transformation allow participants to address difficult topics through team work and structured interactions and challenges. ${ }^{7}$

$7 \quad$ Progress team members Sally Kitch and Cynthia Selin (along with collaborator Lauren Keeler) are pursuing funding to support development and testing of an interactive prototype tool-in the form of a game and/or contingency choice wheel—that will help guide group interaction around the Progress Method tool kits. 
By promoting comparisons across regions and sustainability sectors, the Progress Method also helps stakeholders and decision makers foresee and avoid conflicts among proposed solutions, such as those following the development of biofuels. The Progress Method also encourages continuous collaboration among stakeholders, as well as formative evaluations designed to improve rather than simply assess the final success of a solution, so that stakeholders and decision makers can learn from their mistakes and make adjustments. The evaluation process also recognizes the interconnection between evaluating local or regional solutions and conducting a global-systems change evaluation, as proposed by Michael Quinn Patton (2016). The latter takes a transcultural perspective "that is genuinely global and makes the Earth and the whole human family the unit of analysis" (Patton 2016a; 2016b, p. 380).

\section{A Case Study}

The Progress Method's design may be tested through a planned collaboration between the ASU Progress team and the Kohala Institute in Hawaii, which has historically had a close relationship with ASU. Kohala is a model organization blending research, education, and community engagement through practical application and place-based experiences to address environmental challenges. Because the collaboration has not yet been funded, this discussion conveys the prospective interventions the Progress Method could make rather than the strategies and methodologies actually employed.

Hawaii is the site of many environmental projects because of its isolated geographical location in the middle of the Pacific Ocean, its topography and climatic diversity (encompassing 9 out of 11 climate zones), its abundance of natural resources, and the number of endangered species found on the island. Hawaii also faces many environmental challenges, including: rising seas, accompanied by increasing numbers of droughts; beach erosion, with accompanying shoreline recession and loss of critical habitats, homes, and infrastructure; the lack of nonrenewable resources; and the lack of support for promised community-based subsistence fishing areas for indigenous Hawaiian people, to name a few (Campbell 2014; Anderson et al. 2015; Kimura and Binder 2016; Richmond 2013). The Kohala Institute is one of many community organizations working to address such challenges.

Kohala Institute Executive Director Noe Kalipi was eager to tap the resources of the Progress Method to address several community-based environmental concerns. She was especially interested in the method's focus on problem identification before specific technological choices are made. "While everyone is interested in the systemic big picture," she observed, "often individual motivations are based on protecting a sector/project rather than on identifying the core of a problem before selecting a solution."

The proposed Progress-Kohala team includes Sally Kitch (CEO), Cynthia Selin (Design), Joan McGregor (Function), Noe Kalipi (Implementation), and Gary Dirks (Strategy).The team will also include consultants in science and technology, with appropriate specialties, the digital humanities, environmental history, and the arts, as well as appropriate community organizations.

The initial problem the team intends to address involves an environmental debate on Hawaii Island about ways to balance military training with protecting the environment and accommodating the spiritual and aesthetic perspectives of the mostly indigenous surrounding community. The U.S. military is seeking to update and expand its facilities on the island. From the community perspective, the update reopens the issue of whether the military will be doing live fire training on the island, because such training has impact on the area's environment and sacred cultural sites and brings the potential for unwelcome urbanization in a rural setting. From the military's perspective, U.S. national security of the Asia-Pacific region is paramount. In addition, they have already made significant investment in preserving endangered species and cultural sites and might not wish to do more.

Community organizers connected with the Kohala Institute are also eager to collaborate with the ASU Progress team. They envision expanding the group of leaders beyond those who have typically managed the intersection of military and community priorities. They hope to participate in mediated conversations to reach some kind of consensus, through honing relationships and developing empathy 
across groups for different value systems and conflicting needs. Although the local community cannot actually override the military's right to use their land as they see fit, organizers hope that the Progress Method will level the playing field a bit as stakeholders engage with one another and weigh various options in a series of future scenarios. Discussions in this case could consider the benefits of choosing not to exercise power under particular circumstances.

The benefits from engaging with Progress that Kohala Institute leaders envision include:

- diagnosing stakeholders' priorities, power relationships, assumptions, and interpretations of facts;

- expanding the academic and social knowledge communities-especially indigenous communities-who analyze and synthesize data on the way to decision making;

- developing stakeholders' capacity to listen to and value unfamiliar worldviews and recognize their own biases;

- avoiding culturally disruptive technological innovations;

- building community capacity to consider a full complement of solution possibilities;

- promoting a sense of mutual responsibility among stakeholders;

- facilitating community-viable solutions;

- increasing stakeholders' capacity to prepare for an unpredictable future, adapt to changing circumstances and contexts, and understand and engage in different ways of knowing and imagining the future.

Achieving those goals in the Kohala project, as in other cases, requires meeting several challenges to implementing the Progress Method fully. Among those challenges are: the difficulties of achieving representation of multiple groups without making the interactive, deliberative process too unwieldy; promoting deliberation and mutual respect in an increasingly contentious and litigious age; curating scenarios toward a workable resolution of the problem(s); developing support for incremental change rather than seeking "silver bullets"; avoiding utopian expectations; and managing the costs and time-frame entailed in the Progress program. With regard to the last challenge, a game approach to the Progress Method is designed to create short-cuts that will hasten but not short circuit the deep approach to problem identification and solution selection the method entails.

\section{Scaling Up}

Over time, we envision possibilities for scaling the Progress Method to larger projects with wider implications for the environment. Our collaboration with the Kohala Institute and other local projects will serve as field sites or test beds for prototyping and refining the method and for amplifying its impact through networking. We are also in conversation with Future Earth about integrating the Progress Method into their Knowledge/Action Networks, and plans are underway for collaborating with carbon-capture projects being developed in the Global Institute for Sustainability at ASU. In all of those cases, we hope to help create contexts for grappling with environmental challenges that may seem to be about creating or introducing a new technology or material innovation but are really about significant cultural dilemmas without simple solutions.

There are many cautionary tales in that analytical space. The controversy over the Keystone XL Pipeline, Dakota Access (XL), in the U.S. is an ongoing example of an intertwined environmental and cultural crisis, in which the failure to adequately address the complex problems involved in constructing the pipeline has precluded an easy solution. Now no solution based purely on economic or technical criteria can solve the dilemma.

The crisis is multi-layered. On the surface, the controversy over XL pits the rights of Native peoples to control access to their lands, especially their sacred lands, against the desires of powerful oil companies and governments to transfer Canadian oil to the United States. It is also about the potential for significant environmental damage from such pipelines. Beneath that surface, however, a humanities-centric perspective reveals many other socially significant issues. Human and natural systems conflict in $\mathrm{XL}$, as stakeholders debate the economic versus the environmental value of the 
land the pipeline crosses. Also at stake is a contest between the worth of historical U.S. government treaties with local Indian tribes versus the value of much newer agreements with oil companies. The controversy further pits absent owners and beneficiaries of the pipeline against the local people who must assume all the risks, as well as indigenous values and knowledge against Western technology and the (possibly empty) promise of jobs. The struggle also pits rich oil executives against impoverished indigenous peoples in the U.S. and Canada. In addition, the disagreement over the pipeline is simultaneously a disagreement over the role of government in preserving the environment and regulating the free market.

In short, the XL pipeline controversy is a microcosm of historical and contemporary conflicts in almost every sphere of human life as they intersect with questions about the relative value of autonomous nature and the West's addiction to fossil fuel. The pipeline controversy, then, is a perfect example of an environmental challenge that cannot be addressed by technology alone; indeed, technology is a major cause of the conflict.

What has the U.S. government learned from the months of protests and bitter confrontation at the site of the Dakota Access pipeline? Well, in 2015, President Obama recognized many of these deeper and more significant aspects of the Dakota Access Pipeline project and halted work on it. Four days after his inauguration, however, Donald Trump reversed that action through an executive order that revived the oil companies' permits and threw in a permit for another XL pipeline for good measure. That action, by a self-proclaimed "environmentalist" president (who did not reveal that he had recently owned shares in Energy Transfer Partners, manufacturer of the pipeline) narrowed the problem to its most superficial aspects-the economy needs oil, and the oil industry creates jobs; what's so controversial? The executive order also made no mention of mitigating the social or environmental impact of oil pipelines, with their intrusive presence on the landscape and constant threat of dangerous leaks and methane gas emissions. Trump's order promised to enflame rather than solve the pipeline crisis, even though it entailed no technological change.

The Progress team is not proposing to intervene in problem identification and solution proposal over the XL pipeline. However, the scale and vitriol of the XL pipeline's intertwined cultural, ethical, political, and environmental controversies are what we hope our project's attention to complex human-nature interconnections at the heart of environmental challenges might help to prevent. In addition, while our Futures tool kit does not promise to predict the future, it seems fairly safe to predict that the entangled historical, political, cultural, and environmental concerns at the heart of GEC will never be solved by the kind of problem oversimplification guiding the current U.S. administration's approach to the XL pipeline controversy.

\section{Conclusion: Defining Humanities-Centric Contributions}

Progress is not unique in identifying the importance of expanding stakeholder engagement in addressing environmental challenges. Indeed, stakeholder engagement models for environmental projects based in the social sciences have been used for years. Research into those models suggests, however, that the humanities-centric approach of the Progress Method is both different and potentially more effective in transforming scientific environmental research processes.

Scolobig and Lilliestam (2016) compare the dominant existing social science stakeholder engagement models for environmental decision making: Multi-criteria Analysis, Plural Rationality Theory, and Scenario Construction Approaches. The authors also rate the effectiveness of each model for translating stakeholder perspectives into options for solving environmental problems. Like environmental humanists in general, and the Progress team in particular, the designers of these models believe that science-based approaches are necessary but not sufficient for addressing environmental problems.

There are also other similarities between the dominant social science models and the humanities-centric Progress Method. The Multi-criteria Analysis models (MCA) and Plural Rationality Approaches (PRA), for example, recognize that stakeholders have divergent views on the nature 
and causes of the problem and its solutions. Both models also include methods for integrating divergent stakeholders' views. And obviously the Scenario-Based Approaches (SBA) link stakeholders' perspectives with scenario development, allowing stakeholders to evaluate various future possibilities.

However, there are also many differences between these social science models and a humanities-centric approach like Progress. First, a key mission of the three top categories of social science models is to quantify the qualitative assessments of stakeholders. From a humanities perspective, quantification can be problematic, as it often oversimplifies the complexities of environmental challenges (Sörlin 2013). In addition, quantifying stakeholder views necessitates a priori categorization of possible opinions so that they may be coded and counted. For example, the PRA method deliberately develops a "limited number of socially constructed stakeholders' perspectives: hierarchy, individualism, egalitarianism, and fatalism" (Scolobig and Lilliestam 2016, pp. 53-54). By contrast, a humanities-based investigation like Progress seeks to elicit whatever perspectives stakeholders may have, because new perspectives, or those not previously considered, could be crucial to identifying problems and selecting appropriate remedies. Categorization may follow but should not preclude novel perspectives that emerge in specific situations.

Equally important, researchers' preconceived categories of stakeholder perspectives may impede investigation of unexpected collective issues, such as hidden historical power relationships, competing epistemologies, and conflicts among cultural values that have contributed to environmental problems and must be considered in proposing solutions. From a humanities-centric perspective, such histories and cultural viewpoints come to the table along with the people, but may not be evident before deliberations begin.

In addition, these three social science models treat community stakeholders and experts as separate categories of interested parties. SBAs frequently assume that only experts, and not other stakeholders, will be defining the environmental problems to address and deciding on solutions. Thus, the scenarios constructed by non-expert stakeholders are considered only advisory. SBAs also assume that the "winning" scenarios will be selected not for their creative interconnections but rather for their lowest-cost options (Scolobig and Lilliestam 2016, p. 62). The Progress Method, on the other hand, considers experts as one among many groups of stakeholders who should participate in defining problems, envisioning alternative futures, and collaborating on solutions. As discussed above, experts can have their own biases and preferences-including a preference for technological solutions-which could skew deliberations if they are not accounted for. Experts also need the opportunity to be influenced by other stakeholders' evaluations of the problem and visions of the future. In addition, the Progress Method does not necessarily privilege low technological costs, because of possible contingencies in a particular situation. For example, the best scenarios could combine relatively costly but small-scale, efficient technologies with low-cost policy or cultural supports or changes that reduce new environmental hazards.

Even Scolobig and Lilliestam recognize the limits of the models they survey. Those limitations include failure to address selection bias in choosing stakeholders, power imbalances among stakeholders, the time and resources necessary to do the job democratically, and problems finding impartial facilitators. The authors finally note, "representing and translating the heterogeneity of stakeholders' perspectives and dealing constructively with value-based issues in decision making is far from simple" (Scolobig and Lilliestam 2016, p. 37). Humanities-centric models like Progress may not make the process simple, but they begin with the complexities that existing models do not address, which helps to increase the effectiveness of the strategies and procedures they use to define problems and propose solutions.

From a humanities-centric perspective, focusing on problem identification by expanding the definition of stakeholders, addressing stakeholders' historical conflicts, epistemological divides, entrenched worldviews, and assumptions and expectations, and improving collaboration and communication can be crucial to making sure that problems being addressed are as completely understood and accurate as possible. That is the best way to avoid implementing solutions that 
leave unaddressed the conflicts among priorities, data interpretation, and the deep history of stakeholder investments, all of which threaten to undermine those solutions. Given the complexity of environmental hazards and challenges, including large-scale challenges like the XL Keystone Pipeline controversy, democratizing and complicating problem identification may be among the biggest contributions humanities-centric models like Progress can make in addressing GEC.

Conflicts of Interest: The author declares no conflict of interest.

\section{References}

Anderson, Tiffany R., Charles H. Fletcher, Matthew M. Barbee, L. Neil Frazer, and Bradley M. Romine. 2015. Doubling of Coastal Erosion under Rising Sea level by Mid-century in Hawaii. Natural Hazards 78: 75-103. [CrossRef]

Arabena, Kerry. 2010. All Knowledge is Indigenous. In Tackling Wicked Problems through the Transdisciplinary Imagination. Edited by Valerie A. Brown, John A. Harris and Jacqueline Y. Russell. London: Earthscan, pp. 260-67.

Benneworth, Paul, Magnus Gulbrandsen, and Ellen Hazelkorn. 2016. The Impact and Future of Arts and Humanities Research. London: Palgrave Macmillan.

Brondizio, Eduardo S., Karen O’Brien, Xuemei Bai, Frank Biermann, Will Steffen, Frans Berkhout, Christophe Cudennec, Maria Carmen Lemos, Alexander Wolfe, Jose Palma-Oliveira, and et al. 2016. Re-Conceptualizing the Anthropocene: A Call for Collaboration. Global Environmental Change 39: 318-27. [CrossRef]

Brown, Valerie A., John A. Harris, and Jacqueline Y. Russell, eds. 2010. Tackling Wicked Problems through the Transdisciplinary Imagination. London: Earthscan.

Campbell, John R. 2014. Climate-change migration in the pacific. The Contemporary Pacific 26: 1-28. [CrossRef]

Castree, Noel, William M. Adams, John Barry, Daniel Brockington, Bram Buscher, Esteve Corbera, David Demeritt, Rosaleen Duffy, Ulrike Felt, and Katja Neves. 2014. Changing the Intellectual Climate. Nature Climate Change 4: 762-68. [CrossRef]

Eckersley, Robyn. 1998. The Death of Nature and the Birth of the Ecological Humanities. Organization and Environment 11: 183-85. [CrossRef]

Fleming, A., and S. M. Howden. 2016. Ambiguity: A new way of thinking about responses to climate change. Science of the Total Environment 571: 1271-74. [CrossRef] [PubMed]

Griffiths, Tom. 2007. The Humanities and an Environmentally Sustainable Australia. Australian Humanities Review 43. Available online: www.australianhumanitiesreview.org/archive/Issue-December-2007 /EcoHumanities / EcoGriffiths.html (accessed on 12 October 2017).

Grootjans, John. 2010. White Skin Black Masks: A Personal Narrative on Benevolent Racism. In Tackling Wicked Problems through the Transdisciplinary Imagination. Edited by Valerie A. Brown, John A. Harris and Jacqueline Y. Russell. London: Earthscan, pp. 225-32.

Holm, Poul, Michael Evan Goodsite, Sierd Cloetingh, Mauro Agnoletti, Bedrich Moldan, Daniel J. Lang, Rik Leemans, Joergen Oerstroem Moeller, Mercedes Pardo Buendía, and Walter Pohl. 2013. Collaboration between the Natural, Social and Human Sciences in Global Change Research. Environmental Science and Policy 28: 25-35. [CrossRef]

Kimura, M., and P. M. Binder. 2016. Population and Human Welfare Scenarios for the Island of Hawai'i Up to the Year 2100. Pacific Science 70: 143. [CrossRef]

Kitch, Sally L. 2007. Feminist Interdisciplinary Approaches to Knowledge Building. In Handbook of Feminist Research: Theory and Praxis. Edited by Sharlene Nagy Hesse-Biber. New York: Sage Publications, pp. 123-39.

Little, John C., Erich T. Hester, and Cayelan C. Carey. 2016. Assessing and Enhancing Environmental Sustainability: A Conceptual Review. Environmental Science \& Technology 50: 6830-45.

Patton, Michael Quinn. 2016a. State of the Art and Practice of Developmental Evaluation: Answers to Common and Recurring Questions. In Developmental Evaluation Exemplars: Principles in Practice. Edited by Michael Quinn Patton, Kate McKegg and Nan Wehipeihana. New York: Guilford Press, pp. 1-24.

Patton, Michael Quinn. 2016b. A Transcultural Global Systems Perspective: In search of Blue Marble Evaluators. Canadian Journal of Program Evaluation 30: 374-90. [CrossRef] 
Plumer, Brad. 2013. Corn and Soy Wiping out America's Grasslands at Fastest Pace since the 1930s. The Washington Post. Available online: https://urldefense.proofpoint.com/v2/url?u=http-3A_wapo.st_15uZWev-3Ftid-3Dss-5Fmail2Damp\&d=DwIF-g\&c=AGbYxfJbXK67KfXyGqyv2Ejiz41FqQuZFk4A-1IxfAU\&r=lcVJsKN51Wri2XumfhxIe_ oPgPOeE2ZW781p81D64dc\&m=KDMKIuLWACcUpKaJR1g6WI1Xf4cmJ1Ng28g4NR2oLYE\&s= wAcv9kVijrCegv_dNks4rClbsoPyqUgbzaF6Up1Y2Y8\&e= (accessed on 12 July 2017).

Ramírez, Rafael, and Cynthia Selin. 2014. Plausibility and Probability in Scenario Planning. Foresight 16: 54-74. [CrossRef]

Richmond, Laurie. 2013. Incorporating Indigenous Rights and Environmental Justice into Fishery Management: Comparing Policy Challenges and Potentials from Alaska and Hawaii. Environmental Management 52: 1071-84. [CrossRef] [PubMed]

Rose, Deborah Bird, and Libby Robin. 2004. The Ecological Humanities in Action: An Invitation. Australian Humanities Review 31-32. Available online: www.australianhumanitiesreview.org/archive/Issue-April-2004/ rose.html (accessed on 12 October 2017).

Roy, Eric D., Anita T. Morzillo, Francisco Seijo, Sheila M. W. Reddy, Jeanine M. Rhemtulla, Jeffrey C. Milder, Tobias Kuemmerle, and Sherry L. Martin. 2013. The Elusive Pursuit of Interdisciplinarity at the Human-Environment Interface. Bioscience 63: 745-53. [CrossRef]

Russell, Jacqueline Y. 2010. A Philosophical Framework for an Open and Critical Transdisciplinary Inquiry. In Tackling Wicked Problems through the Transdisciplinary Imagination. Edited by Valerie A. Brown, John A. Harris and Jacqueline Y. Russell. London: Earthscan, pp. 31-60.

Scolobig, Anna, and Johan Lilliestam. 2016. Comparing Approaches for the Integration of Stakeholder Perspectives in Environmental Decision Making. Resources 5: 37. [CrossRef]

Selin, Cynthia, Lucy Kimbell, Rafael Ramirez, and Yasser Bhatti. 2015. Scenarios and Design: Scoping the Dialogue Space. Futures 74: 4-17. [CrossRef]

Sörlin, Sverker. 2013. Reconfiguring environmental expertise. Environmental Science E Policy 28: 14-24.

Stables, Andrew. 2013. The unsustainability imperative? Problems with 'sustainability' and 'sustainable development' as regulative ideals. Environmental Education Research 19: 177-86. [CrossRef]

Van Riper, Carena J., Adam C. Landon, Sarah Kidd, Patrick Bitterman, Lee A. Fitzgerald, Elise F. Granek, Sonia Ibarra, David Iwaniec, Christopher M. Raymond, and David Toledo. 2017. Incorporating Sociocultural Phenomena into Ecosystem-Service Valuation: The Importance of Critical Pluralism. Bioscience 67: $233-44$. [CrossRef]

(C) 2017 by the author. Licensee MDPI, Basel, Switzerland. This article is an open access article distributed under the terms and conditions of the Creative Commons Attribution (CC BY) license (http:/ / creativecommons.org/licenses/by/4.0/). 